\title{
Populorum progressio: desarrollo integral y humanismo cristiano
}

\author{
ILDEFONSO CAMACHO* \\ Facultad de Teología, Granada (España) \\ icamachol@gmail.com
}

\begin{abstract}
Resumen
Se propone en estas páginas hacer una relectura de la que fue primera encíclica de la Iglesia sobre el desarrollo de los pueblos a los 50 años de su publicación. Para ello se selecciona un aspecto de ella: su concepción del auténtico desarrollo, porque es ahí donde, para Pablo VI, radica la aportación más propia y específica de la Iglesia a este problema del que la humanidad entera está tomando conciencia. Esta propuesta hay que leerla en el contexto de aquel tiempo: contexto social (crecimiento sostenido y acceso a la independencia política de muchas antiguas colonias) y contexto eclesial (Concilio Vaticano II). Para Populorum progressio el desarrollo para que sea auténtico ha de ser integral, de todo el hombre y de todos los hombres. Y esto implica superar un concepto demasiado economicista del desarrollo, tan vigente en aquella época; e implica además un desarrollo de la persona abierto a Dios como último horizonte de la plenitud humana. Lebret y Maritain fueron inspiradores indiscutibles en uno y otro aspecto.
\end{abstract}

Palabras clave: desarrollo, desarrollo integral, humanismo, solidaridad.

\section{Populorum progressio: Integral development and Christian humanism}

\begin{abstract}
It is proposed in these pages to make a rereading of the first encyclical of the Church on the development of peoples 50 years after its publication. For this purpose, one aspect of it is selected: its conception of authentic development, because that is where, for Paul VI, the most specific and specific contribution of the Church lies to this problem of which the whole of humanity is becoming aware. This proposal has to be read in the context of that time: social context (sustained growth and access to political independence of many former colonies) and ecclesial context (Second Vatican Council). For Populorum progressio the development to be authentic must be integral, of all man and of all men. And this implies overcoming an overly economistic concept of development, so prevalent at that time; and implies also a development of the person open to God as the ultimate horizon of human fullness. Lebret and Maritain were unmistakable inspirers on both sides.
\end{abstract}

Key words: development, integral development, bumanism, solidarity.

\footnotetext{
* Sacerdote jesuita, doctor en Teología, licenciado en Filosofía y en Ciencias Económicas. Catedrático de Teología Moral (emérito). Entre sus abundantes escritos destacan los libros Ética y responsabilidad empresarial (2013, junto con J. L. Fernández, R. González y J. Miralles), Doctrina Social de la Iglesia: quince claves para su comprensión (2000), Doctrina Social de la Iglesia: una aproximación histórica (19983), y Creyentes en la vida pública: iniciación a la doctrina social de la Iglesia (1994).
} 
Una relectura de la encíclica sobre el desarrollo Populorum progessio (PP, en adelante) 50 años después de su publicación no dejará de ser enriquecedora para nosotros. Es cierto que las condiciones socioeconómicas y políticas de nuestro mundo ya no son las mismas, y que no podemos aplicar a nuestra situación actual todo lo que leemos en PP. ¿Cómo leerla, entonces, hoy?

Creemos que hay que leerla con un doble objetivo: $1^{\circ}$ ) descubrir sus grandes intuiciones que significaron un avance de la Doctrina Social de la Iglesia y una aportación al pensamiento ético de su época; $2^{\circ}$ ) poner de relieve la potencialidad de esas intuiciones en el tiempo posterior que nos separa de su publicación. Nosotros vamos a limitarnos en las páginas que siguen al primero de estos dos objetivos. Más aún, nos vemos obligados por razones de espacio a seleccionar el punto que nos parece de más interés en ambos niveles: y este no dudamos debe ser el concepto mismo de desarrollo. Él debería ser como el prisma desde el que acercarnos a todos los contenidos de PP. Partimos, pues, de la convicción que es el concepto ético de desarrollo la aportación más específica de PP, el cual puede ser iluminado además por toda la tradición cristiana.

\section{QUÉ CONCEPTO DE DESARROLLO: PRIMERA APROXIMACIÓN}

Este ha de ser el punto de partida de esta lectura actualizada. Porque el concepto de desarrollo es nuclear en PP. En efecto, el documento comienza haciendo una breve síntesis de la situación ("Los datos del problema": PP, 6-11) para recordar después cómo la Iglesia, cuando ha evangelizado, lo ha hecho contribuyendo al mismo tiempo al desarrollo de esos pueblos evangelizados (PP, 12). Pero todo esto solo prepara el terreno para afirmar -y esta es para nosotros una afirmación fundamental- que su principal aportación es otra:

Tomando parte en las mejores aspiraciones de los hombres y sufriendo al no verles satisfechos, desea ayudarles a conseguir su pleno desarrollo, y esto precisamente porque ella les propone lo que posee como propio: una visión global del hombre y de la humanidad (PP, 13).

Su aportación propia es su visión de la persona humana. Y de ella deriva su concepción del desarrollo. Estamos, pues, en el núcleo mismo de la encíclica. Pero ¿qué desarrollo? Veámoslo entresacando algunas expresiones del pasaje donde, de un modo magistral, PP sintetiza cómo entiende el desarrollo auténtico: los nn. 14 a 21. 
Es una visión a la vez humana y cristiana. Pablo VI cuida como nadie de no contraponer estas dos dimensiones, que tantas veces en la cultura moderna a todos los niveles se presentan como excluyentes.

Es una visión humana porque su centro es el ser humano: "crecer en humanidad, valer más, ser más" (PP, 15); "que el hombre sea más hombre" (PP, 19); "el verdadero desarrollo, que es el paso para cada uno y para todos de condiciones de vida menos humanas a condiciones más humanas" (PP, 20). Y esto conecta con lo que se percibe como aspiración generalizada hoy, que PP había resumido así: "hacer, conocer, y tener más para ser más: tal es la aspiración de los hombres de hoy" (PP, 6).

Pero es además una visión cristiana porque no se entiende en plenitud sin Dios. Dios está en su origen y en su horizonte o destino. El desarrollo es una vocación": a él está llamado porque "desde su nacimiento ha sido dado a todos como en germen, un conjunto de aptitudes y de cualidades para hacerlas fructificar", actuando con la responsabilidad propia de un ser "dotado de inteligencia y de libertad" (PP, 15). Y es un desarrollo donde el sujeto humano está llamado a superarse a sí mismo, a trascenderse: "Por su inserción en el Cristo vivo el hombre tiene el camino abierto hacia un progreso nuevo, hacia un humanismo trascendente que le da su mayor plenitud; tal es la finalidad suprema del desarrollo personal"'2 (PP, 16). En este trascenderse, abrirse a la trascendencia, está la plenitud humana como "finalidad última" del desarrollo de todo ser humano.

Esta doble dimensión, humana y cristiana, del desarrollo, presuponen una antropología dinámica: la naturaleza humana no se contempla solo como una realidad dada, sino como un punto de partida que Dios pone en todo sujeto para que este la haga crecer y la desarrolle responsablemente. Hay aquí una concepción del desarrollo que va más allá del uso más difundido en la época, cuando el término se aplicaba ante todo al desarrollo de los pueblos, y pone su centro de atención en las personas que componen los pueblos. Una visión adecuada del desarrollo tiene que establecer como pilar de la misma la concepción de la persona.

\footnotetext{
1 Esta afirmación ha sido puesta en primer término por Benedicto XVI en su encíclica conmemorativa de los 40 años de PP Caritas in veritate: "el desarrollo humano integral es ante todo vocación $\mathrm{y}$, por tanto, comporta que se asuman libre y solidariamente responsabilidades por parte de todos" (n. 11; cf. también n. 16).

2 Hemos puesto trascendente, como figura en el texto francés, en lugar de trascendental, que es el adjetivo utilizado en la versión castellana, porque nos parece más coherente con el sentido del texto. Recurrimos al texto francés -y lo haremos en otras ocasionesporque nos consta que es el texto original: en esa lengua trabajaron los redactores y ese fue el texto final que aprobó Pablo VI el 20 de febrero de 1967 (Poupard, 1987: 73). Es decir, aunque el texto oficial es siempre el latino, no siempre es el que más ayuda para entender el sentido del texto tal como fue concebido por sus redactores.
} 
Esto es en otras palabras el "pleno desarrollo humano", que sirve para sintetizar las aspiraciones de tantos pueblos que han accedido a la libertad política a través de los procesos de descolonización, un proceso que la encíclica tiene muy presente por la cercanía temporal (PP, 6). Este es también el desarrollo integral, desarrollo "de todo el hombre y de todos los hombres" (PP, 42). Humano e integral son los dos adjetivos que mejor cuadran para calificar el tipo de desarrollo que PP propone.

\section{POPULORUM PROGRESSIO EN SU CONTEXTO HISTÓRICO: DESARROLLO Y DESCOLONIZACIÓN}

PP no nace de la nada ni puede entenderse aislada del contexto que la vio nacer. $Y$ este no es otro que un mundo que está superando el enorme trauma de la segunda guerra mundial y ante el que se despliegan nuevos horizontes. Por lo que a nuestro tema respecta dos aspectos destacamos.

$\mathrm{El}$ primero es la fase de crecimiento económico sostenido que se inicia con las políticas de reconstrucción de los países azotados por la guerra y en el marco de acuerdos internacionales (acuerdos de Bretton Woods, Plan Marshall) que, a diferencia de lo que ocurrió tras la primera guerra mundial, van a facilitar la cooperación entre Estados y el crecimiento económico. Se entra así en una fase que es conocida como los "Treinta gloriosos".

Simultáneamente se ha producido un proceso de descolonización que lleva a muchos antiguos territorios dependientes de las potencias europeas a acceder a la independencia política. Y una consecuencia explicable de esta nueva situación son las expectativas de un desarrollo económico cuyo referente es el alcanzado por los países más avanzados. Es más, esta meta no se limita a los nuevos Estados independientes, sino que se convierte en el objetivo de iniciativas internacionales. No olvidemos que la Organización de Naciones Unidas ha nacido, no ya solo para prevenir la guerra (como era el caso de la Sociedad de Naciones posterior a la primera guerra mundial) sino también para promover la $\mathrm{paz}^{3}$. Entre sus primeras iniciati-

3 En la Carta de San Francisco, que es el documento fundacional de la Organización de Naciones Unidas (firmado el 26 agosto 1945), se establecen estos objetivos para la ONU: $\left.1^{\circ}\right)$ mantenimiento de la paz y de la seguridad internacionales; $2^{\circ}$ ) coordinación de la cooperación internacional en los planos político, económico, social y cultural; $3^{\circ}$ ) protección y promoción de los derechos y de las libertades fundamentales en el mundo entero. Ya no se trata solo de afrontar los conflictos, sino de construir la paz, mediante la cooperación entre los pueblos y el respeto de los derechos humanos. Por eso la primera tarea emprendida fue la elucidación de esos derechos, lo que dio origen a la Declaración Universal de los Derechos Humanos (aprobada el 10 de diciembre de 1948). 
tivas está la puesta en marcha del Decenio de Naciones Unidas para el Desarrollo ${ }^{4}$.

Por otra parte, estos nuevos ya desde la década de los años 1950 se habían unido para constituir un frente que les permitiese reivindicar su desarrollo. Un momento decisivo para esta iniciativa fue la Conferencia de Bandung (1955), convocada por iniciativa de Egipto, India e Indonesia, del que nacerá seis años más tarde el Movimiento de Países No Alineados (1961). Es en esta época cuando nace y se generaliza la denominación de Tercer Mundo para designar a este conjunto de países, en su mayoría nuevos Estados, que reivindican un verdadero desarrollo en contraposición al mundo capitalista y al socialista, ambos enfrentados como dos bloques en la Guerra Fría. Se atribuye al demógrafo francés Alfred Sauvy el haber sido el primero en utilizar esa expresión en un artículo de L'Observateur de 1952, por analogía con el tercer estado usado en los tiempos de la revolución francesa: "Este tercer mundo ignorado, explotado, despreciado, como el tercer estado, quiere también ser algo". Se refería así famoso texto político ¿Qué es el tercer estado?, publicado por el eclesiástico Emmanuel Joseph Sieyès el mismo año de la revolución francesa (1789) (Calvez, 1992: 5).

Pero lo que se discute en este tiempo, más que el tipo de desarrollo a que se aspira, son las políticas más eficaces para seguir la senda de los países avanzados. Por eso interesa la medición del PIB y de la renta per cápita (sin entrar en discutir si son esos los mejores indicadores), y se comprueba cómo los datos disponibles parecen mostrar que las diferencias entre los países desarrollados y los que no lo son, lejos de disminuir, se acrecientan. Por eso la pregunta obvia sobre qué políticas poner en acción conduce a otra previa: ¿cuáles son los factores que están impidiendo ese desarrollo?

Distintas son las explicaciones que se dan. Señalemos las tres más significativas, ciñéndonos a la época que estamos estudiando, la que rodea a la publicación de PP.

Arthur Lewis, a quien se le considera fundador de la economía del desarrollo, formuló en 1954 su propuesta (Economic Development with Unlimited Supplies of Labour): si el subdesarrollo tiene su causa última en la desarticulación de las economías y las sociedades con un sector moderno abierto a los intercambios internacionales y un sector tradicional en franca descomposición, es preciso crear polos de crecimiento que rearticulen todas las actividades y todos los territorios.

Establecido en diciembre de 1961 para toda la década de los años 1960, sería prolongado en 1970 en un II Decenio. 
Una segunda línea de pensamiento pone el énfasis en la industrialización, que implica en el fondo imitar el modelo de los países más desarrollados como el único camino posible. Y para ello es necesario eliminar los obstáculos apoyándose para ello en las ayudas financieras y en las transferencias de conocimientos y de tecnología. Clásico representante de este enfoque es el economista norteamericano Walt Whitman Rostow (19162003), consejero de la Casa Blanca entre 1961 y 1968. En 1960 publicó una obra que adquirió gran difusión Las etapas del desarrollo. Un manifiesto no comunista. En él describe el proceso histórico a través del cual los países hoy industrializados pasaron desde un estancamiento secular a la situación en que actualmente se encuentran. Rostow un proceso en cinco etapas sucesivas e identifica un momento verdaderamente decisivo (fase de despegue), en el que por fin se eliminan todos los obstáculos a un crecimiento permanente, gracias a la introducción de nuevas técnicas que aumentan la productividad de la agricultura y que permiten una rápida industrialización con altas tasas de ahorro e inversión.

Poco a poco, sin embargo, se abre camino una explicación mucho más radical que se fija más en los obstáculos para el desarrollo que en las vías para alcanzarlo. Según este punto de vista el subdesarrollo es el resultado de la dominación a que están sometidos los países pobres por parte de los países ricos, los cuales demandan a aquellos las materias primas que necesitan para su propio desarrollo y les obligan a comprarles los productos que ellos elaboran. Se produce así un intercambio desigual que favorece sistemáticamente a los países más desarrollados a costa de los subdesarrollados.

Este modelo estructuralista, que se difundió como teoría de la dependencia, conoció dos versiones. La primera es de inspiración marxista y fue formulada ya en 1957 por el economista egipcio Samir Amin que contraponía drásticamente el centro y la periferia. Elaborado desde los presupuestos de la teoría de la revolución de Marx, la salida obvia no sería otra sino la de emprender un proceso de liberación nacional (contra el imperialismo) y de liberación social (contra las clases dominantes internas): y esto exige comenzar por tomar el Estado (revolución política) para abordar después una política de modernización, pero orientada al beneficio de las clases populares. En algunos países este modelo revolucionario se puso en práctica con éxito (China, Corea del Norte, Cuba, Argelia, Vietnam, Mozambique, Burkina Faso, Nicaragua...), mientras que en otros no llegó a triunfar (es el caso de movimientos guerrilleros que fueron aplastados por los respectivos gobiernos en aquellos años).

Una segunda versión de la teoría de la dependencia tiene su representante más cualificado en el economista argentino Raúl Prebisch, el cual sería Secretario General de la Comisión Económica para América Latina 
(CEPAL) entre 1950 y 1963; queda además muy bien reflejada en esos años en la orientación de este organismo en la primera etapa de su vida, lo que provocó que fuera mirado con reservas en los países industrializados y en las instituciones internacionales dominadas por ellos. Las ideas de Prebisch partían de la escasa atención que se prestaba en los organismos internacionales a las economías periféricas en lo que tenían de más específico. Frente a las pretensiones del centro de una teoría económica universal, Prebisch se detiene en explicar la realidad del subdesarrollo de los países latinoamericanos, a pesar de que gozaban de la independencia política desde hacía tiempo. Su tesis consiste en afirmar que, en la división de centro y periferia, se produce un deterioro continuo de la relación real de intercambio de las economías periféricas porque la demanda de productos manufacturados crece mucho más deprisa que la de las materias primas. Para revertir esta tendencia se propone la industrialización para sustituir las importaciones, y se postula además que todo ello se haga en el marco de un proceso de planificación dirigido desde el gobierno ${ }^{5}$.

PP no es ajena a este debate entre distintas interpretaciones del desarrollo. Por eso nos hemos entretenido en presentarlas. Leyendo las páginas de la encíclica no es difícil advertir el eco de algunas cuestiones, sobre todo de las abordadas por Prebisch: el deterioro de la relación real de intercambio como consecuencia de los mecanismos comerciales (PP, 58-59), sobre la necesidad de industrialización (PP, 25), sobre el papel de la planificación (PP, 33), etc.

\section{Populorum PROGRESSIO EN SU CONTEXTO ECLESIAL: EL CONCILIO VATICANO II}

El breve recorrido que acabamos de realizar nos habrá ayudado a contextualizar PP en el escenario mundial. Queda un segundo paso que abordamos ahora: el contexto eclesial. Y este no puede ser otro sino el concilio Vaticano II, y todo lo que él significó para la Iglesia y para el mundo. El Concilio constituyó ante todo un acontecimiento, que se tradujo luego en unos documentos. En estos hubo que llegar a una armonización entre la tradición, que muchos consideraban excesivamente anclada en el pasado, y nuevas formulaciones, que otros pensaban en todo fieles a la más antigua tradición de la Iglesia. En todo caso, el Concilio puso en juego una actitud

5 Estas ideas, que expresó ya en 1949 (Prebisch, 1949), las reformula y completa en 1963 (Prebisch, 1963) en el momento de dejar la CEPAL. En la Introducción expone la génesis de estos dos escritos y ofrece datos de interés sobre las dificultades que encontraron sus ideas en la Organización de las Naciones Unidas, muchas veces tildadas de socialistas y revolucionarias (Prebisch, 1963: VII-XIX). 
oficial de la Iglesia de diálogo con el mundo moderno, de atención a los signos de los tiempos, pero también de dialéctica entre continuidad e innovación que no siempre dejó a todos satisfechos (Madrigal, 2017: 53-64).

En este marco la Constitución Pastoral sobre la Iglesia en el mundo actual, Gaudium et spes (GS en adelante), ocupa un lugar significativo: se trata de un documento inédito en su género porque nunca antes un concilio ecuménico había aprobado un texto de este estilo. El calificativo de "pastoral", con el que se quiso designar esta novedad, tiene que ver con la orientación general que había querido Juan XXIII para el Concilio: no solo la Iglesia ad intra, sino también la Iglesia ad extra, es decir una Iglesia atenta a los problemas del mundo y que se siente capaz de aportar, sin imponerla, su propia luz para abordarlos. GS fue un documento que nació y se gestó durante el Concilio, como expresión de la conciencia que entre los padres se iba fortaleciendo. Sin entrar en su larga gestación ${ }^{6}$, hay que subrayar su enfoque deductivo (se parte de la atención a los signos de los tiempos), su concepción personalista del ser humano como ser social a la luz del Verbo encarnado (capítulos 1 a 3 de la Primera Parte), su importante reflexión sobre las relaciones entre la Iglesia y la sociedad en el contexto del mundo moderno (último capítulo de esa Primera Parte), para desembocar ya en una Segunda Parte que va a recorrer los principales problemas en distintos ámbitos de la vida social (Madrigal, 2017: 95-117). A nosotros nos interesan de esta Parte el capítulo $3^{\circ}$ ("La vida económico-social") y algo del $5^{\circ}$ ("El fomento de la paz y la promoción de la comunidad de los pueblos").

El capítulo sobre la vida económico-social no puede leerse sin tener delante el desarrollo de la Doctrina Social de la Iglesia desde el último tercio del siglo XIX. Solo así se percibe su novedad, así como su conexión con PP. La novedad consiste en colocar en su centro el concepto de desarrollo, un término hasta ahora ausente en los documentos anteriores. Partiendo de la afirmación de que "el hombre es el autor, el centro y el fin de toda la vida económico-social" (GS, 63 a), se despliega después una panorámica novedosa en relación con los documentos sociales anteriores de la Iglesia, tan ceñidos al mundo industrializado y al conflicto entre capitalismo y colectivismo: los problemas socioeconómicos en perspectiva mundial. Las aspiraciones de muchos seres humanos contrastan con los desequilibrios y las desigualdades existentes en una búsqueda desenfrenada de crecimiento económico. Frente a todo esto la "ley fundamental del desarrollo" ha de ser "el servicio del hombre". Dicha ley debe entenderse así:

Hoy más que nunca, para hacer frente al aumento de población y responder a las aspiraciones más amplias del género humano, se tiende con razón a un

6 Una exposición exhaustiva de todo el proceso en: Tucci, 1970. 
aumento en la producción agrícola e industrial y en la prestación de los servicios (...). La finalidad fundamental de esta producción no es el mero incremento de los productos, ni el beneficio, ni el poder, sino el servicio del hombre, del hombre integral, teniendo en cuenta sus necesidades materiales y sus exigencias intelectuales, morales, espirituales y religiosas; de todo hombre, decimos, de todo grupo de hombres, sin distinción de raza o continente (GS, 64).

El "hombre integral" (todo el hombre) y "todo hombre": son las coordenadas de un auténtico desarrollo. Implícitamente hay aquí una crítica al desarrollo vigente en la época: un desarrollo parcial y sesgado por economicista (basta considerar la insistencia en los indicadores económicos, PIB y renta per cápita), y además un desarrollo desigual (que incrementa los desequilibrios entre sectores económicos, dentro de una nación, entre los pueblos de la tierra).

Antes de poner en relación este enfoque con PP no queremos dejar de señalar que todos los temas clásicos de la Doctrina Social, en torno a trabajo y propiedad, pasan a la segunda parte de este capítulo bajo el epígrafe "Algunos principios reguladores del conjunto de la vida económicosocial". De este modo queda claro que el tratamiento de ellos debe hacerse a la luz de este primer principio de desarrollo auténtico (GS, 67-71) ${ }^{7}$.

PP recoge esa doble dimensión del auténtico desarrollo y basa en ella la estructura de toda la encíclica. Sus dos partes llevan por título: "Por un desarrollo integral del hombre" y "Hacia el desarrollo solidario de la humanidad". Ello es signo del deseo de marcar la continuidad con GS. De hecho, se ha afirmado que PP no es sino un intento de desarrollar la doctrina contenida en el Concilio y, particularmente, en GS.

Esto nos lleva a acercarnos a la figura del P. Louis-Joseph Lebret que es reconocido como el principal colaborador de Pablo VI en la redacción de PP. Montini conocía desde sus tiempos como Sustituto en la Secretaría de Estado del Vaticano al dominico francés, el cual pasó en varias ocasiones por su despacho para informarle de sus actividades en pro del desarrollo, obteniendo apoyo de él para el grupo que había fundado, Économie et Humanisme. Así lo testimonia Mr. Poupard (Poupard, 1987: 75-76). Más tarde, ya como arzobispo de Milán (1954-1963), Montini encontró en Lebret y su grupo luz para abordar los problemas socioeconómicos de los que empezó a tomar conciencia en aquella ciudad tan industrial. Y ya como

Resulta hasta cierto punto sorprendente el resumen sistemático que hace de este capítulo L.-J. Lebret en el comentario que publicó de él: no atribuye al desarrollo la centralidad que el texto mismo creemos le concede, y prefiere colocar como punto de partida y primer principio de su síntesis doctrinal el destino universal de los bienes de la tierra (Lebret, 1966: 245-247). 
papa consta que contó pronto con él pidiéndole una nota sobre el texto del entonces llamado "Esquema XVII", que pudo entregar en noviembre de 1963. Poco después fue nombrado por Pablo VI perito conciliar (febrero 1944) (Pelletier, 1996: 400-403).

Desde ese momento su colaboración con el equipo que preparaba lo que terminaría siendo la constitución GS fue intensa (Tucci, 1970: 88-90, 106). Actuó como secretario de la comisión que redactó el anexo 4 del texto de Zurich (que fue estudiado en el aula durante la tercera sesión); colaboró también con Mr. Haubtmann, al que entregó en enero de 1965 un texto que sirvió ya entre la tercera y la cuarta sesión para redactar lo que luego sería la "Exposición Introductoria". Este texto es de especial interés, no solo por su contenido sino porque revela que quien fue llamado principalmente como un perito para temas socioeconómicos aportaba también ideas muy valiosas en los campos de la moral social y de la teología. En concreto, después de poner de relieve las múltiples contradicciones del mundo, Lebret hace gala de un claro optimismo espiritual que tiene que ver con la aspiración universal de la humanidad a ser "más hombre", a "avanzar en humanidad" (Bordeyne, 2005):

El hombre en casi todos los sistemas filosóficos, sociales y políticos actuales se encuentra dividido por contradicciones muchas veces dramáticas. El deseo de ser más hombre, es decir, de realizarse más participando en todos los bienes de la humanidad, económicos, sociales, políticos y culturales, adquiere un alcance universal y mundial (Citado por Bordeyne, 2005: 9).

Esta fórmula de "ser más hombre" es una buena aproximación a lo que Lebret entiende que es el desarrollo. De momento, además, puede decirse que ha dejado su huella en determinados pasajes de $\mathrm{GS}^{8}$. En realidad, Lebret no era un teórico de la justicia, sino un hombre de preocupaciones prácticas, que en su vida había trabajado buscando fórmulas para hacer realidad esa justicia. En esta tarea es donde descubre esa aspiración

8 Para captar todas las referencias hay que acudir al texto latino de GS, porque la expresión "más hombre" o "más humano" no ha sido respetada en las traducciones. Y así se habla de la necesidad de "sabiduría para humanizar (bumaniora fiant) todos los nuevos descubrimientos de la humanidad" (GS, 15c); de la cultura que "hace más humana (bumaniorem reddit) la vida social, tanto en la familia como en toda la sociedad civil" (GS, 53b); de la moral que tiene como razón de ser humanizar a la familia humana y a su historia (ad hominum familiam eiusque historiam bumaniorem reddendam) (GS, 40c); de la necesidad de "construir un mundo más humano (vere humaniorem) para todos los hombres en toda la extensión de la tierra" (GS, 77a). Todo esto debe ser puesto en relación, desde la perspectiva cristológica de GS: "El que sigue a Cristo, Hombre perfecto, se perfecciona cada vez más en su propia dignidad de hombre" (Quicumque Christum sequitur, Hominem perfectum, et ipse magis homo fit) (GS, 41 a). 
tan difundida de "ser más hombre", que entenderá como un "signo de los tiempos" y le servirá para concretar la realización de la justicia.

Podemos concluir este apartado reafirmando que PP no se puede entender sin el Concilio, sin el espíritu que le animó y sin uno de sus documentos más representativos, la GS. Toca ahora avanzar sobre la herencia recibida del Concilio y, más concretamente, de GS.

\section{PROFundizAndo EN EL CONCEPTO DE DESARROllo MÁS ALLÁ de GAUDIUM ET SPES}

La relación de PP con GS es difícil de ignorar. Pero PP no se contenta con repetir lo que se decía allí. Para calibrar sus nuevas aportaciones es útil destacar un cierto trasfondo polémico en PP. Sin duda ya no es el estilo de la Iglesia -especialmente en sus documentos sociales- el de una abierta polémica, y menos aún el de la descalificación o la condena explícita (como ocurrió en concilios anteriores) ${ }^{9}$. Este talante que deseaba Juan XXIII es el que se impuso en el Concilio, aunque no sin encontrar resistencias ${ }^{10}$. De él resulta un estilo más propositivo que polémico, pero detrás de las propuestas se adivinan críticas frente a posturas muy vigentes en la época. Con este criterio se nos ocurre que el concepto de desarrollo de PP subraya tres exigencias que son fáciles de identificar: 1) es tarea, no mero resultado del proceso económico; 2) no puede limitarse al crecimiento económico; 3) ha de ser integral en sentido pleno, es decir, acorde con un verdadero humanismo cristiano.

9 Juan XXIII había dado directrices muy claras en el discurso que pronunció el día de la apertura del Concilio (Gaudet Mater Ecclesia, 11 octubre 1962): un texto en el que había trabajado largamente y del que solía decir que "era enteramente harina de su propio costal" (Sale, 2012: 47-50). Propuso como tema central del Concilio "la eficaz presentación del sagrado depósito”, pero puntualizando el enfoque más pastoral, porque "una cosa es el depósito y otra las formas de expresión". Preocupan más las formas de expresión que los contenidos doctrinales. El deseo de diálogo queda plasmado en la insistencia de Juan XXIII en aplicar "el remedio de la misericordia" a la hora de reprimir los errores. Todavía el espíritu positivo del papa Roncalli queda reflejado en la queja que expresa sobre los "profetas de calamidades", probable alusión a personas de su entorno que dudaban de la oportunidad de un concilio.

10 No todos se encontraron a gusto con estas orientaciones, todavía recientemente P. Pasqualucci llega a afirmar que "la Gaudet Mater Ecclesia ha marcado el comienzo de una fractura, que con el Concilio se ha convertido en una vorágine y con el postconcilio en un abismo" (Pasqualucci, 2007: 35). Este mismo autor concluye su obra con esta conclusión que desarrolla en el último capítulo: "Capítulo 11 - Conclusión: la Alocución roncalliana aparece anómala y viciada en cuanto a la intención, llena de espíritu modernista, y como consecuencia de éste objetivamente penetrada de pelagianismo y de milenarismo". 
4.1. El desarrollo como tarea: las responsabilidades de unos y otros

Cuando pasábamos revista a las principales teorías para explicar el desarrollo veíamos tras ellas la sombra de los dos grandes modelos socioeconómicos: uno, que todo lo confiaba a las fuerzas del mercado en un contexto de libertad económica, frente a otro, que ponía el acento en la intervención de los poderes públicos para orientar la actividad económica. Si excluimos los extremos (el liberalismo más puro y el colectivismo de estricta planificación), la cuestión clave es la de delimitar el papel del Estado y sus políticas socioeconómicas. Podría traducirse así: ¿basta promover el crecimiento con la confianza de que ello redundará en un mejor nivel de bienestar para todos, o hay que establecer políticas más complejas que orienten el modo de crecer y se ocupen también de la distribución de la renta producida?

PP opta decididamente por esta segunda opción. Y ello se puede ver plasmado en el mismo esquema del documento. Creemos que la división del texto en dos partes, que quiere hacerse eco sin duda de la doble exigencia de GS para todo desarrollo (de todo el hombre / de todos los hombres; en otras palabras, integral/solidario), más bien dificulta la comprensión de la dinámica interna del texto. Porque, si uno atiende a la lógica interna del contenido prescindiendo de la división en dos partes, descubre un esquema distinto. Hemos querido plasmarlo en el cuadro siguiente:

\begin{tabular}{|c|c|}
\hline $\begin{array}{l}\text { ESQUEMA PROPIO } \\
\text { DEL DOCUMENTO }\end{array}$ & $\begin{array}{l}\text { REELABORACIÓN } \\
\text { SEGÚN CONTENIDO }\end{array}$ \\
\hline $\begin{array}{l}\text { PARTE PRIMERA: Hacia un desarro- } \\
\text { llo integral del hombre } \\
1^{\circ} \text {. Los datos del problema }\end{array}$ & Ver: los datos del problema (PP, 6-11) \\
\hline $\begin{array}{l}2^{\circ} \text {. Aportación de la Iglesia al } \\
\text { desarrollo }\end{array}$ & $\begin{array}{l}\text { Ju2gar: doctrina sobre el desarrollo (PP, } \\
12-21 \text { ) }\end{array}$ \\
\hline $\begin{array}{l}3^{\circ} . \text { Acciones concretas a empren- } \\
\text { der }\end{array}$ & $\begin{array}{l}\text { Actuar: la tarea a emprender por los } \\
\text { países en desarrollo (PP, 22-42) }\end{array}$ \\
\hline $\begin{array}{l}\text { PARTE SEGUNDA: Hacia el desarro- } \\
\text { llo solidario de la humanidad } \\
1^{\circ} . \text { Deber de solidaridad } \\
2^{\circ} . \text { Deber de justicia social } \\
3^{\circ} . \text { Deber de caridad universal }\end{array}$ & $\begin{array}{l}\text { Actuar: las responsabilidades de los paí- } \\
\text { ses desarrollados y de las instituciones } \\
\text { internacionales (PP, 43-80) }\end{array}$ \\
\hline
\end{tabular}


Dos observaciones al respecto:

- El esquema básico responde al conocido de ver/juagar/actuar, muy utilizado en aquellos años: implica el cambio desde un modelo más deductivo a otro más inductivo, que parte más del análisis de la realidad que de los principios doctrinales ${ }^{11}$.

- En este nuevo esquema que muy destacada la importancia de la acción (casi las tres cuartas partes del texto); y, dentro de esta, a las responsabilidades del mundo desarrollado e instituciones básicamente controladas por él (toda la Parte segunda del documento según su esquema propio).

La parte dedicada a las responsabilidades que corresponden a lospaises en desarrollo (PP, 22-42) merece una atenta lectura. No podemos detenernos en todos los detalles, pero una visión de conjunto nos permitirá calibrar las dimensiones de lo que se propone:

- No se excluye una reforma agraria (tantas veces contemplada en los programas de desarrollo): concretamente, hay sugerencias para ella en los pasajes referidos a la propiedad y sus limitaciones (PP, 22-24).

- Se insiste en la necesidad de la industrialización como forma de alcanzar una cierta consistencia económica, tema que no puede desconectarse de las propuestas mencionadas más arriba de sustitución de las importaciones (PP, 25).

- Las reformas deben ser audaces e innovadoras (PP, 32), porque además esa es la única vía para evitar que los intentos revolucionarios, tan en boga en aquellos años, encuentren justificación (PP, 31).

- Hay que combinar la iniciativa privada con la actividad planificadora del Estado, al cual corresponde fijar objetivos y establecer políticas, no para anular, sino para encauzar a la iniciativa privada (PP, 33).

- Hay que conjugar crecimiento económico con progreso social, de forma que el desarrollo esté "al servicio de la persona" (PP, 34). En este sentido la educación básica ha de ser "el primer objetivo de un plan de desarrollo" (PP, 35).

11 El método ver-juzgar-actuar se remonta al método de revisión de vida, surgido en el seno de las propuestas pastorales de la Juventud Obrera Católica (JOC) que animaba Joseph Cardijn en Bélgica en los años 1930. Posteriormente la revisión de vida fue asumida por la Acción Católica. La encontramos recomendada por Juan XXIII en su encíclica Mater et magistra, nn. 236-237. Y el mismo Concilio en su decreto Apostolicam actuositatem sobre al apostolado de los laicos (n. 29) recomendaba el ver-juzgar-actuar como una meta de la formación de estos para el apostolado. 
- Es importante la salvaguarda de las culturas autóctonas, con muchas potencialidades (PP, 40), que se verán muchas veces amenazadas por la tentación materialista "que les viene de los pueblos ricos" (PP, 41).

- El modelo último tiene que ser mixto porque "la sola iniciativa individual y el simple juego de la competencia no serían suficientes para asegurar el éxito del desarrollo" con el riesgo de que aumente la riqueza de los ricos y la miseria de los pobres (PP, 33). En este sentido, el modelo de capitalismo que acompañó a la revolución industrial, "liberalismo sin freno", no puede ser aceptado (PP, 26) ${ }^{12}$.

Pero la iniciativa de los propios países en desarrollo no es suficiente, si no se cuenta con los países ya desarrollados, sobre los que recaen responsabilidades nada desdeñables. Estas responsabilidades están concretadas en tres deberes, a los que se dedican sucesivamente los tres apartados en que se divide la Parte segunda. Su presentación sintética recoge muy bien el alcance de cada uno de ellos:

[...] deber de solidaridad, en la ayuda que las naciones ricas deben aportar a los países en vía de desarrollo; deber de justicia social, enderezando las relaciones comerciales defectuosas entre los pueblos fuertes y débiles; deber de caridad universal, para la promoción de un mundo más humano para todos, en donde todos tengan que dar y recibir, sin que el progreso de los unos sea un obstáculo para el desarrollo de los otros (PP, 44).

12 Este pasaje debe ser leído con cautela porque la versión oficial española desfigura su sentido original al traducir en tiempo presente lo que en el texto francés va en pasado. En realidad no se está haciendo una condena general del capitalismo o del liberalismo (aunque es frecuente ver este texto citado en ese sentido), sino un rechazo de aquella forma de capitalismo o de liberalismo que sirvió de marco histórico a la revolución industrial (García Gómez, 1968: 29; Camacho, 1998: 386-387). Véase una traducción revisada teniendo en cuenta el texto francés (en cursiva los verbos incorrectamente traducidos): "Pero, por desgracia, sobre estas nuevas condiciones de la sociedad ha sido construido un sistema que consideraba el lucro como motor esencial del progreso económico, la competencia como ley suprema de la economía, la propiedad privada de los medios de producción como un derecho absoluto, sin límites ni obligaciones sociales correspondientes. Este liberalismo sin freno conducia a la dictadura, justamente denunciada por Pío XI como generadora de 'el imperialismo internacional del dinero'. No hay mejor manera de reprobar un tal abuso que recordando solemnemente una vez más que la economía está al servicio del hombre. Pero si es verdadero que un cierto capitalismo ha sido la causa de muchos sufrimientos, de injusticias y luchas fratricidas, cuyos efectos duran todavía, sería un error atribuir a la industrialización misma los males que son debidos al nefasto sistema que la acompañaba" (PP, 26). El texto oficial latino emplea también los verbos en tiempo pasado. 
Tampoco aquí vamos a entrar en los detalles, porque nos perderíamos en ellos. Pero sí queremos destacar los trazos dominantes de PP en relación con el desarrollo como tarea, no ya de los países en desarrollo, sino de toda la comunidad mundial:

- El pasado del colonialismo está presente en PP (están todavía recientes los procesos de descolonización). Sin dejar de reconocer ciertas acciones beneficiosas de las potencias colonizadoras, PP deplora una situación en la que dominaban los intereses de estas (PP 7), creando relaciones de dependencia (PP, 52) y división ("un muro de separación entre colonizadores e indígenas", PP, 63).

- En esta misma línea hay también en PP una crítica al sistema de libre comercio, que ha contribuido a aumentar las desigualdades entre los pueblos. Tampoco aquí se quiere sentar una tesis general sobre el mercado. Solo se critican sus consecuencias cuando "las partes [que intervienen en el mercado] se encuentran en condiciones demasiado desiguales de potencia económica", como es el caso en las relaciones comerciales con los países poco desarrollados. Por eso, "la regla del libre cambio no puede seguir rigiendo ella sola las relaciones internacionales" y "es el principio fundamental del liberalismo, como regla de los intercambios comerciales, el que está aquí puesto en cuestión" (PP, 58).

- Todo eso (herencia colonialista, libre comercio como regla) contrasta con lo que la encíclica desea para las tareas a emprender. En estas tareas ha de dominar la solidaridad, término que aparece hasta 19 veces en el texto y que designa uno de los dos rasgos definitorios de un auténtico desarrollo. La solidaridad es un hecho (típico de un mundo cada vez más interdependiente), pero es también un deber (PP, 17, 48). Como deber se traduce en la asistencia de los países ricos a los pobres: esta es la exigencia que más se subraya, insistiendo en que ha de ser desinteresada (PP, 44, 64) para no derivar en una forma de neocolonialismo (PP, 52). Es importante destacar el carácter obligatorio de esta ayuda, porque no es más que una consecuencia de la doctrina sobre el uso de los bienes superfluos (PP, 49). La solidaridad debe traducirse en espíritu de colaboración, que supere tantas rivalidades de antaño; igualmente debe expresarse en la hospitalidad (PP, 67) y en la apertura al diálogo (PP, 73).

- En este nuevo marco los pueblos en desarrollo han de ser artífices de su destino, lo que no es sino el reverso de la dependencia colonial (PP, 65). Se está pensando en un mundo distinto, construido sobre nuevos principios. 
- Este mundo nuevo tiene como escenario propio la comunidad de pueblos que había sido propuesta por Juan XXIII en su encíclica sobre la paz, y que es una de las aportaciones más novedosas de la misma: en nuestro mundo moderno esta comunidad debe tener su propia entidad, porque es más que una yuxtaposición de pueblos que colaboran entre sí como iguales desde el respeto recíproco. Es ahí donde nacen el concepto de bien común universal y es también desde ahí desde donde surge la propuesta de una autoridad mundial ${ }^{3}$. Pablo VI se sitúa en esta estela. Aunque hay más referencias a las relaciones bilaterales o multilaterales entre pueblos ricos y pobres (sobre todo en la Parte segunda), no se olvida este nuevo horizonte. Se recoge la invitación que el propio Pablo VI hizo en su intervención ante la Asamblea General de las Naciones Unidas el 4 de octubre de 1965: "¿Quién no ve la necesidad de llegar así progresivamente a instaurar una autoridad mundial que pueda actuar eficazmente en el terreno jurídico y en el de la política?” (PP, 78). Relacionado con esto hay que ver también la propuesta de crear un Fondo mundial (que Pablo VI ya pidió en su viaje a Bombay) "alimentado con una parte de los gastos militares, a fin de ayudar a los más desheredados", que sería al mismo tiempo "símbolo e instrumento" de una verdadera colaboración mundial (PP, 51).

- Todo ello se puede sintetizar en aquella fórmula de PP que luego se ha repetido tanto: "El desarrollo es el nuevo nombre de la paz", una paz "que no se reduce a la ausencia de guerra", sino que "se construye día a día, en la instauración de un orden querido por Dios, que comporta una justicia más perfecta entre los hombres” (PP 76). Resuenan aquí tanto el capítulo final de GS ("el fomento de la paz y la promoción de la comunidad de los pueblos") y la encíclica de Juan XXIII sobre la $\mathrm{paz}^{14}$.

No se puede decir que falten sugerencias concretas que Pablo VI considera necesario poner en marcha con urgencia ${ }^{15}$. Sin entrar en polémicos

\footnotetext{
13 A todo esto dedica Juan XXIII el capítulo IV de Pacem in terris ("Ordenación de las relaciones mundiales”) en sus números 130-141 (Camacho, 1998: 278-281). Benedicto XVI hace suya la propuesta de una autoridad mundial en el nuevo contexto de la globalización (Caritas in veritate, n. 67).

14 "El desarrollo es el nuevo nombre de la paz": esta formulación expresa, en opinión de alguien tan cualificado como Mr. Poupard, la verdadera conclusión de toda la encíclica (Poupard, 1987: 77).

15 El adjetivo "urgente" (PP, 3, 22, 32, 47) y el sustantivo "urgencia" (PP, 1, 7, 28, 29, $53,80)$ son recurrentes en el texto y han sido señalados como novedosos en una encíclica en la que preocupa más "ponerse a la obra" que quedarse más bien en consideraciones doctrinales.
} 
debates PP distingue y conjuga la doble responsabilidad: de los propios países en desarrollo y de los desarrollados y ricos: para los primeros propone medidas que suponen un modelo mixto; respecto a los segundos, insiste en la responsabilidad que han contraído.

\subsection{El desarrollo no puede limitarse al crecimiento económico}

Del cómo pasamos al qué. Promover ¿qué desarrollo? Es la otra gran cuestión de PP. Desarrollo integral y solidario. Tenemos la impresión que, a diferencia de GS, en PP el desarrollo integral tiene un carácter más englobante: "El desarrollo no se reduce al simple crecimiento económico. Para ser auténtico debe ser integral, es decir, promover a todos los hombres y a todo el hombre" (PP, 14). Desarrollo integral se opone explícitamente a crecimiento económico.

No se entra en polémica abierta con los enfoques entonces dominantes en todas las estrategias de desarrollo, que implícitamente identifican desarrollo con crecimiento económico. ¿Qué otra cosa significa el que sea el PIB per cápita el principal indicador para orientar las políticas y medir el nivel de desarrollo? Es más, no estamos solo ante un sistema de medición: subyace toda una concepción de la persona, de lo que se considera su bienestar o su felicidad. Ser más equivaldría a tener más, a acumular más.

La constatación de este estado de cosas es el punto de partida de la encíclica para proponer un concepto alternativo de desarrollo. Y este concepto ya lo dejamos recogido más arriba como "el paso para cada uno y para todos de condiciones de vida menos humanas a condiciones más humanas" (PP, 20). En el "para todos" está incluido ya el desarrollo solidario, aunque el hacerlo posible exige la implicación efectiva de muchos actores, como también hemos visto en el apartado anterior.

Resulta clarificador para entender la insistencia de PP en un desarrollo no solo económico sino integral acercarse a la figura del dominico P. Lebret. No solo colaboró en la redacción de GS, como ya hemos visto. Tuvo además un papel crucial en la elaboración de PP. Así lo reconoció Mr. Paul Poupard ya en el acto de presentación oficial del texto: al recordar cómo este ha conocido hasta siete redacciones sucesivas y que en él han contribuido un gran número de expertos, añade que el P. Lebret merece "una mención muy especial"16. Y, aunque entre los papeles que se conservan de Lebret no hay rastro de textos redactados por él, sí se encuentran en su diario referencias más o menos explícitas a la tarea que le había sido encomendada. Las que han sido recogidas por Denis Pelletier (1996: 406-408)

16 La Documentation Catholique, n. 1492 (16 avril 1967) col. 673-674. 
y por Marc Feix (2007: 13-15) nos informan de que PP ya estaba en gestación durante el Concilio. Lebret alude al encargo recibido varias veces: $\mathrm{y}$ lo hace entre el 27 de abril de 1964 y el 9 de octubre de 1965, es decir, desde antes que comenzara la tercera sesión conciliar. El 3 de abril de 1965 anota que el texto ya está listo en latín. Pero, después de algunas dudas sobre la fecha más oportuna para su publicación, Pablo VI opta por esperar a que concluya el Concilio. De hecho, PP ve la luz el día de Pascua de 1967 (26 de marzo), cuando ya Lebret había muerto ${ }^{17}$. A pesar de la noticia que él da, el texto debió ser reelaborado una vez concluido el Concilio, aunque solo sea por las numerosas notas que se incluyen de $\mathrm{GS}^{18}$.

Estos datos sobre la intervención del P. Lebret en la redacción de PP, pueden confirmarse ahora con el análisis interno del texto comparándolo con la obra más conocida del dominico, Dynamique concrète du développement, publicada en 1961.

Permítasenos una breve presentación de esta obra, en la que "casi ninguna frase $(. .$.$) se ha escrito sin tener en cuenta nuestros propios estudios$ sobre el terreno" (Lebret, 1966: 27). Es su experiencia directa en países de América Latina y África lo que le da pie para ofrecer "una dinámica concreta" para el desarrollo: "concreta" porque no deriva de una formulación matemática, como pretenden muchos economistas que solo miran a la realidad desde esa perspectiva, sino que es fruto de una aproximación "polivalente" capaz de captar factores extraeconómicos decisivos para el desarrollo de pueblos concretos. Esta dinámica es concebida como una armonización de las necesidades y las potencialidades de cada pueblo, que es lo que Lebret ha empleado como palancas para promover el desarrollo en los lugares en que trabajó.

Pero al dar forma a esta dinámica concreta Lebret no puede ignorar dos cosas: que el desarrollo se ha convertido en una aspiración universal en este tiempo; que el sentido del término mismo encierra no pocas confusiones. La aspiración básica de la humanidad ha sido siempre a un estado mejor. Pero en la época moderna, gracias a los avances de la ciencia y de la técnica, esta aspiración se ha traducido, no en "saber más" o en "valer más", sino en un "tener más". Y este "tener más" aboca a la humanidad

17 Su muerte se produjo casi un año antes: el 20 de julio de 1966. De hecho ya durante la última sesión del Concilio su participación estuvo muy limitada debido a su deteriorado estado de salud.

18 Se pueden contar hasta quince citas, de las cuales trece corresponden a la primera parte. Cipriano Calderón, en su crónica de Ecclesia indica que la redacción definitiva se emprendió en noviembre de 1966 y que estaba lista en febrero de 1967 (Calderón, 1967: $35)$. 
en una civilización claramente materialista. Por eso la obra que comentamos se ve obligada a comenzar por una clarificación del término mismo de desarrollo, una preocupación que también encontramos en PP.

Lebret se encuentra ante dos concepciones enfrentadas de desarrollo:

Para unos el desarrollo es 'mecanicista', para otros 'orgánico'; para unos se trata de añadir producciones, para otros es la elevación humana en todas las capas de la población.

Es plantear de nuevo el problema de una economía que tenga valor en sí misma y el de una economía humana que valga para todo el hombre y para todos los hombres. En el primer caso su finalidad es de orden cuantitativo; en el segundo, de orden humano (Lebret, 1966: 45).

Todavía una referencia más. También Lebret recurre al adjetivo "integral" cuando habla de la colaboración y solidaridad entre los pueblos propone un "desarrollo integral armónico". Y lo explica así:

'Integral' significa: para todos los hombres y de todos los hombres, en todos los sectores de lo necesario; ‘armónico' significa: orientado de tal modo que los crecimientos de ramas y los crecimientos globales no lleven a crear desequilibrios y hacer imposible la respuesta a las necesidades, lo cual es el primer problema del desarrollo" (Lebret, 1966: 49).

No hemos hecho sino espigar las primeras páginas del libro de Lebret. Ello basta para convencernos de la sintonía de este enfoque con algunas de las páginas de PP, especialmente aquellas en que se opone a una definición economicista del desarrollo. Incluso en las formas de expresión hay coincidencias inocultables.

El texto de PP cita una sola vez a Lebret, al que presenta como "un eminente experto" (PP, 14). Y se transcribe un párrafo suyo para justificar que el desarrollo no puede ventilarse solo en el ámbito de la economía:

No admitimos que se separe lo económico de lo humano, que se separe el desarrollo de las civilizaciones en que se produce. Lo que cuenta para nosotros es el hombre, cada hombre, cada grupo de hombres, la humanidad entera" (PP, 14) (Lebret, 1966: 32) ${ }^{19}$.

Sorprendentemente no se le vuelve a citar, cuando en el párrafo que precede inmediatamente a este encontramos casi en su literalidad la definición que da PP del desarrollo. Véase el texto:

19 El texto reproducido no es el que se encuentra en PP, sino la versión castellana de la obra de Lebret, que es la que venimos usando. 
El desarrollo es el objeto mismo de la economía humana en el sentido que le ha dado el grupo 'Économie et Humanisme'. Y este sentido es el siguiente: la disciplina (a la vez del conocimiento y de la acción) de paso, para un pueblo determinado y para los grupos que lo constituyen, desde una fase menos humana a una fase más humana, al ritmo más rápido posible, con el coste menos elevado posible, teniendo en cuenta la solidaridad entre los grupos y los pueblos" (Lebret, 1966: 32) ${ }^{20}$.

Todavía PP concretará más el alcance de este pasar de condiciones de vida menos humanas a otras más humanas. Es un texto que, aunque algo extenso, merece la pena reproducir:

Menos humanas: las carencias materiales de los que están privados del mínimum vital y las carencias morales de los que están mutilados por el egoísmo. Menos humanas: las estructuras opresoras, ya provengan del abuso del tener o del abuso del poder, de la explotación de los trabajadores o de la injusticia de las transacciones. Más humanas: el remontarse de la miseria a la posesión de lo necesario, la victoria sobre las calamidades sociales, la ampliación de los conocimientos, la adquisición de la cultura. Más humanas: el aumento en la consideración de la dignidad de los demás, la orientación hacia el espíritu de pobreza, la cooperación en el bien común, la voluntad de paz. Más humanas todavía: el reconocimiento por parte del hombre de los valores supremos y de Dios, que de ellos es la fuente y el fin. Más humanas por fin y especialmente: la fe, don de Dios acogido por la buena voluntad de los hombres y la unidad en la caridad de Cristo, que nos llama a todos a participar como hijos en la vida del Dios vivo, Padre de todos los hombres (PP, 21).

No es un texto retórico: cada uno de los elementos que se menciona encuentra su eco en otros pasajes de la encíclica. Las carencias materiales se yuxtaponen al egoísmo como carencia moral: es un reflejo de la crítica hecha a las consecuencias de esa exacerbación del "tener más". El abuso del tener o del poder alimenta muchas veces las distintas formas de explotación de los más débiles, sean trabajadores o pueblos enteros. Y las condiciones más humanas tienen los dos primeros "escalones": en un desarrollo personal, que incluye lo material, pero se complementa con el acceso a la educación y a la cultura; y en un desarrollo social, basado en relaciones de convivencia que se apoyan en el respeto a los otros y la cooperación entre todos. Solo después de todo eso el desarrollo humano se abre a la dimensión trascendente: primero, y de una forma más genérica, a Dios; luego, al Dios que se nos revela en Jesucristo. Con eso estamos ya en lo más sustancial del desarrollo integral tal como creemos debe entenderse en PP.

20 Esta definición se repite casi literalmente un poco más adelante: Lebret, 1966: 46. 
4.3. El desarrollo auténtico ha de ser desarrollo integral en sentido pleno

Si en una primera aproximación al desarrollo PP es deudora del P. Lebret (desarrollo no solo económico, no economista), para completar la visión del mismo no se puede ignorar la influencia de Jacques Maritain.

Los contactos de Montini con Maritain venían de lejos. Montini se interesó desde muy pronto por el pensamiento del filósofo francés. Ya en los años 1920 fue Montini quien tradujo al italiano la obra en que Maritain formula por primera vez de forma inequívoca su crítica radical del mundo moderno, todavía no sin alguna nostalgia medieval: Tres reformadores. Lutero, Descartes, Rousseau, publicada en 1925. Luego difundió entre los intelectuales italianos Humanismo integral (aparecida en 1936), incluso antes de que estuviera disponible la versión italiana de esta obra (Campanini, 2015: 56. 190).

Más allá de los encuentros personales o de los contactos directos entre Montini y Maritain, es indudable la afinidad intelectual que les une. Entre las preocupaciones que comparten se cuenta la de redefinir el lugar de la Iglesia en la sociedad moderna y el papel de los cristianos en ella. Esto lo vivió Juan Bautista Montini ya en su juventud, cuando su padre Giorgio Montini desempeñaba un papel relevante en el Partito Popolare de Luigi Sturzo, en una época de difíciles relaciones con el fascismo y con la Santa Sede. Y es precisamente en este tiempo cuando muchos dirigentes de dicha formación política buscaban inspiración en el filósofo francés, en unos años en que su propuesta era objeto de enconada polémica y de fuertes críticas (por ejemplo, por parte de la revista Civiltà Cattolica, tan cercana a la Santa Sede) (Viotto, 2014: 120-123).

Este intento de resituar a los cristianos en la nueva sociedad tiene como punto de apoyo su idea del verdadero bumanismo. La nueva cristiandad no es sino el intento de recuperar el verdadero humanismo, el humanismo cristiano, con el que la sociedad moderna quiso acabar, pero quiere recuperarlo en un modelo distinto al de la cristiandad. Para ello recurre Maritain al concepto de ideal histórico, que es algo propio de una etapa, pero de ningún modo universalizable ${ }^{21}$. La cristiandad medieval tenía su propio ideal histórico. Su característica distintiva era la unidad (un fondo común de pensamiento) que tendía a generar una unidad religiosa y política, una unidad que solo podía hacerse realidad si era de orden sagrado. El orden

21 Por "ideal histórico" entiende Maritain "una imagen prospectiva que designa el tipo particular, el tipo específico de civilización a que tiende una determinada edad histórica" (Maritain, 1999: 167-168). Esto supone un profundo sentido histórico porque el mundo avanza de modo irreversible, una postura que se opone frontalmente al eterno retorno propio de las cosmovisiones paganas. 
temporal quedaba entonces, no solo sometido al espiritual, sino al servicio de este y reducido a mero medio o instrumento. Era además una sociedad muy jerárquica y diferenciada. En el fondo, era como construir el reino de Dios en la tierra (Maritain, 1999: 184-194).

Contra este ideal reaccionó la sociedad moderna desde el Renacimiento y la Reforma proponiendo una rehabilitación antropocéntrica del hombre. En este humanismo antropocéntrico Dios ha dejado de ser el centro del hombre: ahora es el propio hombre el centro del hombre y de todas las cosas. Pero este humanismo, no por lo que tiene de humanismo sino por lo que tiene de antropocéntrico, es un humanismo inhumano que conduce a la "tragedia del humanismo" (Maritain, 1999: 55).

Ahora bien, si somos consecuentes con las nuevas condiciones históricas, la reacción no puede ser volver al ideal histórico de la cristiandad sino construir un nuevo ideal histórico, el de la nueva cristiandad, que conserve los principios de toda civilización vitalmente cristiana pero los traduzca a las nuevas condiciones.

En la nueva cristiandad la idea central no será ya el imperio de lo sagrado que Dios posee sobre todas las cosas, sino la de la santa libertad de la criatura unida a Dios por la gracia. Esto se vive en una sociedad que es plural, y no homogénea. En ella queda reconocida la autonomía de lo temporal: lo temporal no es ya un medio (como ocurría en la cristiandad medieval), pero tampoco es el fin último, sino solo un fin intermedio, pero verdadero fin. La construcción de la ciudad temporal ya no es una obra divina que el hombre ha de realizar en la tierra, sino una obra humana a realizar en la tierra con sus propios medios y su trabajo, solo que bajo la inspiración de algo divino que es el amor. Este es el humanismo integral o teocéntrico, cuyas características son opuestas al liberalismo o al humanismo antropocéntrico, e inversas también a las del ideal histórico medieval (Maritain, 1999: 205-250).

Maritain se detiene en analizar lo que es el reino de Dios y se ocupa de distinguirlo tanto de la Iglesia como del mundo:

Creemos que en espera del más allá de la historia en que el reino de Dios se realizará en la gloria de la plena manifestación, la Iglesia es ya el reino de Dios en el orden llamado espiritual y en estado peregrino y crucificado; y que el mundo, el orden llamado temporal, este mundo encerrado en la historia, es un dominio compartido y ambiguo, a la vez de Dios, del hombre y del príncipe de este mundo (Maritain, 1999: 164-165).

Como se ve, en la propuesta de Maritain, el humanismo viene a ser como la columna vertebral: un humanismo que, para ser auténtico, tiene que ser teocéntrico. A este humanismo le llama él "humanismo integral": 
En este nuevo momento de la historia de la cultura cristiana, la criatura no quedará negada o aniquilada ante Dios; tampoco sería rehabilitada sin Dios o contra Dios; sería rehabilitada en Dios (...). Que la criatura sea realmente respetada en su vinculación con Dios y porque todo lo tiene de él. Humanismo sí, pero humanismo teocéntrico, enraizado allí donde el hombre tiene sus raíces; humanismo integral, humanismo de la Encarnación (Maritain, 1999: 104).

El rasgo más característico de este nuevo humanismo sería la "rehabilitación de la criatura en Dios". Se trata de pensar en unos términos nuevos la relación entre Dios y su criatura. Este texto que sigue marca la diferencia con la concepción tradicional:

Entendemos, pues, que, si para una civilización cristiana ingenua (es decir, basada en la unidad originaria e ingenua del hombre), el progresar hacia Dios consistía ante todo en levantarle un trono sobre la tierra, de acuerdo con los derechos de su majestad, en cambio para una civilización cristiana que ya no puede ser ingenua y en la que el hombre debe recobrar su unidad perdida recuperando el control de sí mismo bajo el instinto de la gracia, el progresar hacia Dios consistirá, ante todo (según creo), en preparar para el hombre las condiciones terrenales de una vida, en que el amor soberano pueda descender y realizar en el hombre y con él una obra divinamente humana" (Maritain, 1999: 106).

Si retornamos ahora a PP, no costará trabajo descubrir el eco de este humanismo en sus páginas. Una vez cita la encíclica el libro de Maritain, cuyo humanismo califica como "humanismo pleno", que queda así conectado con el desarrollo integral de PP:

Es un humanismo pleno el que hay que promover. ¿Qué quiere decir esto sino el desarrollo integral de todo el hombre y de todos los hombres? Un humanismo cerrado, impenetrable a los valores del espíritu y a Dios, que es la fuente de ellos, podría aparentemente triunfar. Ciertamente el hombre puede organizar la tierra sin Dios, pero 'al fin y al cabo, sin Dios no puede menos de organizarla contra el hombre. El humanismo exclusivo es un humanismo inhumano' No hay, pues, más humanismo verdadero que el que se abre al Absoluto, en el reconocimiento de una vocación, que da la idea verdadera de la vida humana. Lejos de ser la norma última de los valores, el hombre no se realiza a sí mismo si no superándose" (PP, 42) ${ }^{22}$.

\footnotetext{
22 La cita entre comillas corresponde a la obra de H. de Lubac, El drama del humanismo ateo, publicada en París en 1944. Este planteamiento ha sido recogido con fórmulas muy rotundas por Benedicto XVI en la Conclusión de Caritas in veritate, n. 78.
} 
La propuesta de desarrollo integral de PP va mucho más allá de la superación de una concepción economicista de este. Es una propuesta profunda e inequívocamente cristiana, íntegramente cristiana. Pablo VI ha sido capaz de hacer esta síntesis, con ayuda de otros pensadores como hemos visto, pero en la línea de un verdadero humanismo, que no necesita negar al hombre para afirmar a Dios ni negar a Dios para afirmar al hombre: porque Dios se sitúa en la plenitud del hombre, nunca en menoscabo de este, menos aún como su negación. Es una respuesta coherente con nuestra convicción de que Pablo VI es un verdadero humanista.

\section{UNAS PALABRAS FINALES}

El problema del desarrollo de los pueblos sigue en pie, incluso agravado en el marco de la globalización. Tampoco h encontrado nuestro mundo un equilibrio a la hora de conjugar a Dios y al ser humano haciéndolos coexistir en pacífica convivencia.

PP quiso abordar conjuntamente este doble reto, no como dos problemas independientes. Lo hizo en las coordenadas de su tiempo, con la confianza de que la aportación de la Iglesia era digna de hacerse oír: en esto el espíritu del Concilio, recién celebrado, es patente. El Concilio y GS constituyen un momento de esta reflexión. PP significa un paso más. En sus páginas encontramos propuestas concretas, que no son neutrales a los debates de aquel momento. Pero se quiere ir más allá: para no trabajar a ciegas hay que elucidar qué desarrollo queremos, y esto implica saber preguntarse también que tipo de sociedad queremos construir y al servicio de qué tipo de persona. PP no da por buenas las ideas subyacentes a las políticas de desarrollo en acción. Más aún, la antropología nunca es ajena a la teología: la imagen del hombre depende de la imagen de Dios. Por eso es ahí donde radica lo que Pablo VI considera la principal aportación, no ya de su encíclica, sino de la Iglesia en su historia: la de promover un auténtico humanismo, un humanismo integral, trascendente y abierto a Dios. Y esta no es una cuestión que hay que considerar superflua cuando apremian problemas más urgentes; tampoco hay que suponer su respuesta como obvia o fácil, ni como inútil de abordar en un mundo tan secular. El mensaje de Pablo VI sigue vigente: empeñarse en una visión a la vez humana y cristiana de la realidad, verdaderamente humana por ser cristiana.

\section{REFERENCIAS}

-Bordeyne, Ph. (2005). L'appel à la justice face au désir d'être plus homme. L'apport de Louis-Joseph Lebret à la rédaction de Gaudium et spes. Oikonomia, (2), 6-14. 
-Calderón, C. (1967). La nueva encíclica de Pablo VI. Ecclesia , (1.335), 25-27.

-Calvez J.-Y. (1992). El tercer mundo: todo un mundo dentro del mundo. Aspectos sociales, políticos, internacionales. Bilbao: Mensajero.

-Camacho, I. (1998). Doctrina social de la Iglesia. Una aproximación histórica. Madrid: Paulinas.

-Campanini, G. (2015). Il filosofo e il monsignore. Maritain e Montini, due intellettuali a confronto. Bologna: Centro Editoriale Dehoniano.

-Feix, M. (2007). Du juste prix dans la réflexion sur l'économie du Père Lebret et dans l'encyclique Populorum progressio. Revue d'éthique et de théologie morale, (243), 9-48.

-García Gómez, M. (1968). Un nuevo tono en el magisterio social de la Iglesia. Teología de un nuevo género literario. En M. García Gómez (Ed.), Teología y sociología del desarrollo. Comentario a la "Populorum progressio" (pp. 3-35). Madrid: Razón y Fe.

-Lebret, L.-J. (1966). Dinámica concreta del desarrollo. Barcelona: Herder [original de (1961), Dynamique concre $\square$ te du de $\square$ veloppement. Paris: $\mathrm{E} \square$ conomie et Humanisme, Les $\mathrm{E} \square$ ditions Ouvrie $\square$ res].

-Lebret, L.-J. (1968). La vida económica y social y la promoción de la comunidad de los pueblos. En AA. VV., La Iglesia en el mundo actual. Constitucio $\square$ n "Gaudium et spes”. Comentarios al Esquema XIII (pp. 219-263). Bilbao: Desclée de Brower.

-Madrigal, S. (2017). El giro eclesiológico en la recepción del Vaticano II. Santander: Sal Terrae.

-Maritain, J. (1999). Humanismo integral. Problemas temporales y espirituales de una nueva cristiandad. Madrid: Palabra [citamos esta edición corrigiendo a veces la traducción según el texto original francés, (1936). Humanisme intégrale. Problèmes temporels et spirituels d'une nouvelle chrétienté. Paris: Fernand Aubier].

-Pasqualucci, P. (2007). Giovanni XXIII e il Concilio Ecumenico Vaticano II. Analisi critica de la lettera, dei fondamenti, dell'influenza e delle consquenze della "Gaudet Mater Ecclesia”, allocurione di apertura del concilio, di Giovanni XXIII. Roma: Editrice Ichthys.

-Pelletier, D. (1996). Économie et Humanisme. De l'utopie communautaire au combat pour le tiers-monde 1941-1966. Paris: Cerf.

-Poupard, P. (1987). Le père Lebret, le pape Paul VI et l'encyclique Populorum progressio, vingt ans après. Istituto Paolo VI. Notiziario, (14), 71-84.

-Prebisch, R. (1949). El desarrollo económico de América Latina y algunos de sus principales problemas. Recuperado de http://repositorio.cepal.org/handle/11362/30088

-Prebisch, R. (1963). Hacia una dinámica del desarrollo latinoamericano. México: Fondo de Cultura Económica.

-Sale, G. (2012). Giovanni XXIII e la preparazione del Concilio Vaticano II nei diari inediti del direttore della "Civilta $\square$ Cattolica" Padre Roberto Tucci. Milano: Jaca Book. 
-Tucci, R. (1970). Introducción histórica y doctrinal a la Constitución Pastoral. En Y. Congar \& M. Peuchmaurd (Dirs.), La Iglesia en el mundo de hoy. Constitución pastoral "Gaudium et spes". Volumen II: Comentarios (pp. 37-159). Madrid: Taurus.

-Viotto, P. (2014). Paolo VI - Jacques Maritain. Un'amicizia intelletuale. Roma: Studium.

Sumario: 1. Qué concepto de desarrollo: primera aproximación; 2. Populorum progressio en su contexto histórico: desarrollo y descolonización; 3. Populorum progressio en su contexto eclesial: el Concilio Vaticano II; 4. Profundizando en el concepto de desarrollo más allá de Gaudium et spes; 4.1. El desarrollo como tarea: las responsabilidades de unos y otros; 4.2. El desarrollo no puede limitarse al crecimiento económico; 4.3. El desarrollo auténtico ha de ser desarrollo integral en sentido pleno; 5. Unas palabras finales; Referencias. 